\title{
Learning areas for holistic education: kindergarten teachers' curriculum priorities, professional development needs, and beliefs
}

\author{
Alfredo Bautista*, Siew-Chin Ng, David Múñez and Rebecca Bull
}

*Correspondence:
Alfredo.Bautista@nie.edu.sg
National Institute
of Education, Education \&
Cognitive Development
Lab, Nanyang Technological
University, Singapore,
Singapore

${ }^{*}$ Correspondence: AlfredoBautista@nie.edu.sg of Education, Education \& Cognitive Development University, Singapore, Singapore

\begin{abstract}
Contemporary kindergarten curriculum frameworks emphasize the importance of promoting children's holistic development, thereby focusing on both academic and non-academic learning areas. This exploratory study was conducted with a sample of 123 in-service kindergarten teachers in Singapore. The goals were to investigate the following: (1) how teachers prioritized the importance of the various learning areas of the 'Nurturing Early Learners' curriculum framework; (2) teachers' professional development (PD) needs regarding these learning areas; and (3) the extent to which teachers with different beliefs about children and how they learn differed in their prioritizations and PD needs. Data were collected through an online questionnaire and analyzed using non-parametric techniques. Results indicated that (1) academic and nonacademic areas were found to be intertwined in teachers' priority rankings, although Social and Emotional Development was the top learning area for most teachers; (2) teachers reported high PD needs in all learning areas, especially in Discovery of the World and Aesthetics and Creative Expression; and (3) teachers holding more traditional beliefs tended to prioritize academic areas. No differences were found when comparing teachers' responses according to their level of education, age, and years of teaching experience. We discuss the findings in light of prior literature, the implications and limitations of the study, and lines for further research.
\end{abstract}

Keywords: Kindergarten teachers, Learning areas, Holistic education, Curriculum, Professional development, Beliefs

\section{Background}

The quality of early childhood education (ECE) has been predominantly defined and measured in terms of two interlinked types of factors: structural factors (e.g., class size, teacher-child ratio, physical environment, teachers' qualifications) and process factors (e.g., quality of teacher-child interaction, nature of center leadership) (Bertram et al. 2016; Ishimine et al. 2010). Recently, scholars have emphasized the need to take into consideration a third set of factors that relate to the notion of orientational quality (Wall et al. 2015). Such factors include ECE practitioners' educational and curricular priorities, their learning goals and professional development (PD) needs, the understanding of their own professional roles, as well as their educational beliefs and values (Anders 2015). Similar to structural factors, the importance of orientational factors lies in their

(c) The Author(s) 2016. This article is distributed under the terms of the Creative Commons Attribution 4.0 International License (http://creativecommons.org/licenses/by/4.0/), which permits unrestricted use, distribution, and reproduction in any medium, provided you give appropriate credit to the original author(s) and the source, provide a link to the Creative Commons license, and indicate if changes were made. 
potential to affect process quality. For instance, teachers' own views on the curriculum or their beliefs about children and how they learn may have strong influence over the quality of instructional practices and teacher-child interaction (Pianta 2016).

This exploratory study analyzes several dimensions of orientational quality with a sample of kindergarten teachers in Singapore. The curriculum framework designed by Singapore's Ministry of Education (MOE), titled 'Nurturing Early Learners' (NEL) (MOE 2013), emphasizes the importance of promoting children's holistic development, thereby focusing on both academic and non-academic learning areas (Tan 2007). In this paper, we investigate the following: (1) how kindergarten teachers prioritize the importance of the various learning areas of the NEL framework; (2) teachers' PD needs regarding these learning areas; and (3) the extent to which teachers with different beliefs about children and how they learn differed in their prioritizations and PD needs. Additionally, we compare teachers' responses according to their level of education, age, and years of teaching experience.

\section{Preschool education in Singapore: the learning areas for holistic education}

One of the measures recently adopted in many countries to enhance the quality of their ECE systems has been the design of new curriculum frameworks, which have set up ambitious goals for young children (Chan et al. 2009; Gananathan 2011; Pence and Pacini-Ketchabaw 2010). Moving away from either providing caring services or preparing children academically for primary school, contemporary kindergarten education curriculum frameworks aim at promoting holistic learning and development through the integration of academic and non-academic areas (Bennett and Kaga 2010; Khoo 2010). It is widely recognized that high-quality preschool education must equip children not only with good socio-emotional competencies, values, and dispositions, but also with early academic knowledge and skills that will help in forming their abilities for lifelong learning (Wall et al. 2015).

Similar shifts at the curricular level have occurred in Singapore. In 2003, with the goal of improving the overall quality of Singapore's ECE sector, the Ministry of Education (MOE) launched the 'Kindergarten Curriculum Framework', which listed the aims and desired outcomes for preschool education (note that the term 'preschool' in Singapore refers to both kindergarten and child care centers). Clearly inspired by the works of influential scholars such as Jean Piaget, Lev Vygotsky, John Dewey, and Jerome Bruner, the framework was based on six key theoretical underpinnings: (1) A holistic approach to development and learning; (2) Integrative learning; (3) Children as curious, active, and competent learners; (4) Adults as interested supporters in learning; (5) Interactive learning; and (6) Play as a medium for learning to encourage children to think widely, be more engaged and explore ideas thoughtfully (MOE 2003). Prior to launching this framework, a large-scale experimental study revealed that the implementation of these principles at the classroom level produced improvements in Singapore children's problem-solving and social skills, listening, and language processing (Shanmugaratnam 2003).

The 'Kindergarten Curriculum Framework' emphasized that while early academic competencies in numeracy, literacy (reading and writing), or science are necessary and should not be overlooked, the enduring effects of social and emotional competences are of even greater importance for the holistic development of a life-long learner (Tan 
2007). According to compelling ECE research studies (e.g., Eggum-Wilkens et al. 2014; Gmitrová and Gmitrov 2003), the framework argued that children learn best in supportive environments that encourage exploration and discovery through play and interaction. This perspective was in stark contrast with the tradition of many kindergartens in Singapore, whose main goal was to prepare students for the Primary One curriculum (Khoo 2010). The new approach was also based on research showing that ECE programs exclusively focused on formal academic skills were more likely to provide opportunities for children to fail and develop a higher dependency on adults, thus fostering negative perceptions of their own potential (see Katz 2015).

In 2012, the 'Kindergarten Curriculum Framework' was revised and published under the name of 'Nurturing Early Learners' (NEL). While the revised framework was based on similar theoretical underpinnings, it also specified a series of general 'Desired Learning Outcomes' of education in Singapore (i.e., becoming a confident person, a selfdirected learner, an active contributor and a concerned citizen), as well as the 'Key Stage Outcomes' specific to preschool education (i.e., knowing what is right and what is wrong, being willing to share and take turns with others, able to relate to others, being curious and able to explore, able to listen and speak with understanding, comfortable and happy with themselves, having developed physical co-ordination, healthy habits, participate in and enjoy a variety of arts experiences, as well as love their families, friends, teachers, and school) (MOE 2013). In addition, the NEL framework outlined several learning dispositions to be inculcated in children which included perseverance, reflectiveness, appreciation, inventiveness, sense of wonder and curiosity, and engagement.

The NEL proposed that these outcomes, skills, and dispositions could be achieved through six learning areas, all of which were conceived to be essential for holistic development (MOE 2013). These learning areas encompass Aesthetics and Creative Expression, which allow children to engage in creative play and self-expression through art, music and movement; Discovery of the World, through which children observe, ask questions and make sense of the world around them; Language and Literacy, which allow children to participate in language-related activities that develop abilities to listen with understanding and to communicate with others; Motor Skills Development, which fosters the development of gross and fine motor skills that improve sense of balance, physical co-ordination and spatial awareness; Numeracy, which allows children to understand and apply mathematical concepts, skills and processes; and Social and Emotional Development, which is understood as the basis for children to manage their feelings, thoughts, and behaviors (MOE 2013). Six inter-related volumes, each covering one of these six learning areas, were published in 2013 to guide the practices of preschool educators and providers.

Within the Singapore context, Aesthetics and Creative Expression, Motor Skills Development, and Social and Emotional Development are typically considered non-academic learning areas, as students' knowledge in these domains is not assessed formally during compulsory education. The remaining areas, Discovery of the World, Language and Literacy, and Numeracy, tend to be regarded as academic because they relate to the subjects of Science, Language/Literacy, and Mathematics from primary school onwards.

Consistent with international trends in curriculum design, the NEL framework recommended ECE principals and teachers to adopt the 'thematic approach,' where rather 
than focusing on isolated concepts or topics, learning activities revolve around boarder themes, also referred to as 'big ideas' in the literature (Parsons 2004). The rationale is that integrated learning allows children to connect elements from different domains and create networks of interdisciplinary relationships, which fosters deeper and more complex approaches to knowledge (Todd 2010). The NEL framework defines integrated learning activities as those that "provide opportunities for children to be involved in more than one learning area" (MOE 2013, p. 84).

Despite the push of current ECE curricula for the ideas of holistic learning and curriculum integration, international research has indicated that preschool teachers tend to prioritize certain learning areas over others. In a survey study conducted in one high-need urban school district in New York state, Piotrkowski et al. (2000) found that preschool and kindergarten teachers tended to prioritize social competencies and interpersonal skills over academic knowledge. For example, 'Peer relations' was considered to be absolutely necessary at kindergarten entry by $58 \%$ of preschool teachers and $68 \%$ of kindergarten teachers. In contrast, academic-oriented skills such as 'Count to 50 or more' were only considered essential by $2 \%$ of preschool teachers and $2 \%$ of kindergarten teachers. Interestingly, parents rated all academically oriented skills as more important than teachers did. Perhaps as a reflection of their concerns for their children's academic success, most parents believed that being able to communicate in English and acquire basic knowledge and skills relating to mathematics and science were more important than developing socio-emotional competencies or deep approaches to learning.

Similar findings have been reported in a more recent survey study conducted by Abry et al. (2015). Drawing on a nationally representative sample of children and educators in the United States, this study indicates that preschool and kindergarten teachers tend to view interpersonal competencies as more important than academic skills. Other studies have shown that teachers' priorities are context specific and might vary as a result of socio-political, cultural, or curricular factors. For example, Bassok et al. (2015) have recently shown how kindergarten teachers in the US started to emphasize much more on academic competencies in the decade following the No Child Left Behind Act of 2001.

Within the Singapore context, Lim-Ratnam (2013) has described how the pressures of Singapore's high-stakes examination system in compulsory education often contribute to a strong focus in academic skills during preschool years. Many parents view preschool education as a preparation for primary school. Hence, many expect that preschool teachers will teach their children how to read and write in at least two languages (English and their own mother tongue). Parents also typically expect children to be familiar with numbers, be able to count, add, and subtract. Their anxieties reflect the strong emphasis that Asian societies place on children's academic excellence (see also Berthelsen et al. 2011; Ellis 2014; Li and Rao 2005). These societal expectations obviously run counter to curricula that are holistic in nature. Preschool teachers in countries like Singapore, therefore, struggle with contradictory demands and expectations: whether pleasing parents with worksheets, homework, and formal academic activities or teaching according to the guidelines of the current national curriculum (Lim-Ratnam 2013).

The question of how kindergarten teachers prioritize the importance of the various learning areas of NEL has not been investigated within the Singapore context. We also know very little about teachers' perceived PD needs regarding these learning areas, 
which Wall et al. (2015) have conceptualized as a key dimension of the construct orientational quality. Do Singapore kindergarten teachers perceive the need to receive further training in the various learning areas of NEL? If so, to what extent? Are there any areas with particularly high needs for further training? In the following section, we describe the framework that we adopted to tackle these questions.

\section{Teachers' professional development needs regarding NEL's learning areas}

There is widespread agreement within the ECE international community that employing professional teachers and staff and providing them with opportunities for continuous training are essential factors of high-quality preschool programs (OECD 2015). For this reason, among others, policymakers in many countries have started to invest increasing resources in on-going PD for preschool teachers, in order to better provide them with the knowledge, skills, and competencies they need to become successful educators (Chan et al. 2009). In the last two decades, the Singapore Government has also implemented various measures to improve the preparation and quality of preschool teachers (MOE 2013). During the early 2000, the minimum professional qualification to work as a preschool teacher was holding a 'Certificate in Preschool Teaching,' which required $470 \mathrm{~h}$ of training. Today, most preschool teachers have either attained or are completing the 'Diploma in Early Childhood Care and Education-Teaching,' which involves 700 training hours.

PD is a relatively new concept to the Singapore's preschool sector. It was only in 2013 that a masterplan for preschool staff was introduced by the Early Childhood Development Agency (ECDA). The Continuing Professional Development masterplan (ECDA 2013) provides ECE personnel with structured pathways to develop and update their professional knowledge, skills, and dispositions, while customizing PD to the specific needs and progressive levels of competencies of each teacher. Currently, ECDA strongly encourages all preschool teachers to participate in a minimum of $20 \mathrm{~h}$ of PD per year. Both formal and informal (center-based) PD activities are recognized (ECDA 2016).

Since its establishment, ECDA has conducted a wide variety of PD initiatives in collaboration with other training providers and agencies such as SEED Institute and Science Centre Board. These PD initiatives (e.g., workshops, courses) have been varied with regard to content focus, duration, and delivery style. With regard to content focus, the courses and workshops offered by ECDA aim at developing preschool educators' knowledge and skills in the learning areas outlined in the NEL framework. In 2016, for example, 22 courses and workshops were offered (ECDA 2016). A descriptive analysis carried out for the purposes of this paper identified that 17 of them (77\%) were directly related to one specific learning area, two (9\%) were related to several learning areas, and three (14\%) were related to other topics not covered explicitly in the NEL framework. More specifically, six workshops and courses (27\%) were related to Aesthetics and Creative Expression, followed by five (22\%) related to Discovery of the World, three (13\%) to Language and Literacy, three (13\%) to Numeracy, two (9\%) to Motor Skills Development, and two (9\%) to Social and Emotional Development. Examples of these courses and workshops are 'Development of Numeracy in Early Childhood Education' (Numeracy), 'Fun Elements of Art' (Aesthetics and Creative Expression) and 'Discovery of the World through Inquiry-based Learning' (Discovery of the World). We speculate that 
the strategy of privileging certain areas over others might be a measure purposefully adopted by the local PD providers to strengthen teachers' knowledge and skills in areas that are rather secondary within pre-service preparation programs (e.g., Aesthetics and Creative Expression and Discovery of the World), and with which teachers tend to feel less confident (Berthelsen et al. 2011).

International research shows that much of the PD available to preschool teachers is based on the one-size-fits-all approach, which has limited potential to foster teacher learning (Darling-Hammond et al. 2010). A recent review of the literature conducted by Schachter (2015) has described the content of the PD initiatives offered to early childhood educators. Out of the 73 intervention and process studies considered in the analysis, 54\% of initiatives focused on areas related to language and literacy instruction, followed by $38 \%$ focused on socio-emotional development. Interestingly, less than $10 \%$ of the PD offered to preschool educators addressed areas such as numeracy/mathematics, science, or health.

Scholars currently agree that one of the features of effective PD is being coherent with and responsive to teachers' perceived needs (Bautista and Ortega-Ruíz 2015). Hence, before designing and implementing PD, it is essential to know what teachers themselves want to learn. Because no published research has analyzed the PD needs of Singapore kindergarten teachers, the present study aims to fill this gap in the literature. In the next section, we frame the third topic investigated in this study, namely teachers' beliefs on education, which constitutes another key dimension of orientational quality (Wall et al. 2015). More precisely, our goal was to explore the extent to which teachers with different beliefs about children and how they learn (traditional vs progressive) differed in their priorities and PD needs with regard to NEL's learning areas.

\section{Teachers' beliefs about children and how they learn}

The educational literature has consistently shown the importance of teachers' beliefs about children and how they learn, which play a central role in shaping teachers' expectations, interactions with children, instructional practices, classroom environment, and even children's learning and achievement (Hur et al. 2015; Wall et al. 2015). There is some evidence that teachers who hold more progressive, child-centered beliefs about education and knowledge acquisition tend to have classrooms with more positive social climate, allowing children to construct their own knowledge instead of emphasizing on rote learning (Pianta 2016; Stipek and Byler 1997). Some studies have shown that, as a result of both generational and educational differences, younger and more junior teachers tend to hold beliefs and conceptions of teaching and learning that are comparatively more progressive than those held by older (and thus, more experienced) educators, who typically tend to be more content-focused and teacher-centered (e.g., Bautista et al. 2010; Pajares 1992).

Research conducted specifically at the preschool level has shown that teachers who hold more progressive, child-centered beliefs tend to share more positive emotional experiences with students, as compared to teachers that exhibit more traditional, adultcentered beliefs (Driscoll and Pianta 2010). In turn, students of teachers holding progressive, child-centered beliefs tend to display greater motivation for learning, lower 
anxiety, and higher competence in language and problem-solving than their peers in more authoritative classroom settings (Stipek and Byler 1997).

In a study conducted in the United States, Lara-Cinisomo et al. (2011) found that the differences in the educational backgrounds between kindergarten teachers and child care educators were associated to differences in their beliefs about children and how they learn. Kindergarten teachers were typically bachelor's degree holders, whereas child care educators did not have any specific degree requirement beyond a high school diploma. Interestingly, the authors reported that the participating kindergarten teachers tended to display more traditional and academically oriented beliefs, showing stronger agreement with ideas such as "children should be instructed in recognizing the single letters of the alphabet, isolated from words." In contrast, child care educators advocated for children being exposed to both academic and non-academic areas through meaningful activities and to guide their own learning experiences more freely. These educators tended to agree with beliefs such as "children should be allowed to select many of their own activities from a variety of learning areas that the teacher has prepared." Note that these findings differ from the results obtained by Piotrkowski et al. (2000), described above.

Research has also suggested that preschool educators' beliefs about children and how they learn might be influenced by their prior PD experiences. For example Fuligni et al. (2009) found that PD focused on family child care allowed teachers to enhance their authoritative or democratic beliefs about children, whereas PD related to child development enhanced the positive emotional climate in the classroom. More recently, Hur et al. (2015) have investigated the predictors of teachers' child-centered beliefs with a large sample of preschool educators in the United States. The results showed that teachers' perceived collegiality and influence had positive associations with job-related satisfaction, which in turn was positively associated with child-centered beliefs.

\section{Goals and research questions}

In light of the literature presented above, the present exploratory study had three goals. The first goal was to analyze how Singapore kindergarten teachers prioritized the importance of the different areas of the NEL curriculum framework in children's learning and development. Based on prior research conducted in Asia (Berthelsen et al. 2011; Ellis 2014; Li and Rao 2005; Lim-Ratnam 2013), we anticipated that teachers would prioritize academic areas over non-academic areas due to social expectations and family pressures. The second goal was to investigate teachers' PD needs in terms of the learning areas of the NEL framework. Given the lack of research in this area within Singapore, we could not articulate specific expected results. Finally, the third goal was to explore the extent to which preschool teachers with different beliefs about children and how they learn (from more traditional to more progressive beliefs) differed in how they prioritized the importance of NEL's learning areas and their own PD needs regarding these areas. As no prior study has investigated these particular topics, we did not have specific expected results. The three research questions (RQs) addressed in the study were as follows:

RQ1 How do Singapore kindergarten teachers prioritize the importance of the various learning areas described in the NEL framework in children' learning 
and development?

RQ2 What are these teachers' perceived PD needs regarding these various learning areas?

RQ3 Do teachers with different beliefs about children and how they learn (traditional vs progressive) differ in their priorities and PD needs with regard to the learning areas?

Additionally, we analyzed whether demographic variables (teachers' level of education, age, and years of teaching experience) were associated with different prioritizations of the learning areas, with different PD needs, or with different beliefs on education and how children learn.

\section{Methods}

Participants

Participants were 123 in-service kindergarten teachers in Singapore, teaching K1 and/ or K2 children ( 4 and 5 years old, respectively). The teachers were recruited once their corresponding centers $(N=60)$ agreed to take part in a large-scale, longitudinal study about the impact of preschool education in Singapore, titled 'Singapore Kindergarten Impact Project' (SKIP). All participants were females, ranging from 20 to 62 years of age $(M=34.41, \mathrm{SD}=10.65)$. Their professional experiences as kindergarten teachers ranged from 0.3 to 25 years $(M=7.22, \mathrm{SD}=5.68)$. All teachers held certifications relating to Early Childhood Education: 11 teachers held a certificate (8.9\%), 73 a diploma (59.3\%), 36 a university degree (29.3\%), and three a master's degree (2.4\%).

\section{Procedure}

Data were collected at one time-point. Participants were asked to complete an online questionnaire that was distributed via Qualtrics ${ }^{\mathrm{TM}}$ Online Survey Software. The questionnaire included several standardized scales (looking at teachers' personality, motivation, beliefs about children's education, and prior PD experiences) as well as various items that were designed and piloted in-house to address the research questions of our longitudinal project. On average, teachers took $18 \mathrm{~min}$ to complete the questionnaire. The teachers provided informed consent and were informed that the data would be analyzed and reported anonymously.

\section{Measures}

Below we describe the items and standardized scales that were used to measure the constructs involved in the present study. Note that prioritizations of the learning areas and PD needs were studied through single item measures.

\section{Prioritization of learning areas}

This item was designed in-house. Teachers were asked to rank seven learning areas according to their perceived level of importance in early childhood education. More precisely, the question posed was: We know all curriculum areas are important. However, if we asked you to rank their importance, how would you do it? Please rank the following areas from 1 (most important) to 7 (least important). Each learning area was to be 
assigned one value. Each value (1-7) could be used only once. The areas presented to the teachers were as follows:

- Aesthetics and Creative Expression;

- Discovery of the World;

- Language (English and Mother Tongue);

- Literacy (Reading and Writing);

- Motor Skills Development;

- Numeracy; and

- Social and Emotional Development.

Note that the third and fourth learning areas were created based on the NEL's Language and Literacy learning area. This distinction was made in order to have a more finegrained understanding of teachers' own priorities, as we understood that the importance of having a good verbal command of a language versus reading/writing in such a language might be different for teachers.

\section{Perceived PD needs regarding the learning areas}

This item was also designed in-house to address a specific question about PD needs related to learning areas of the NEL in Singapore. Teachers were asked to indicate their level of need for further training in each of the above-mentioned learning areas. The question was worded as follows: Thinking of your own professional development needs, please indicate the extent to which you need to learn further about the following areas. A 4-point scale was used to collect the data:

1. No need for further training at all;

2. Low level of need;

3. Moderate level of need; and

4. High level of need.

\section{Beliefs about children and how they learn}

We used the 'Modernity Scale' (Schaefer and Edgerton 1985) to measure kindergarten teachers' beliefs about children and how they learn. This instrument is reliable and valid, having been used in a number of large-scale ECE studies (NICHD Early Child Care Research Network 2006). The scale allows situating teachers on a continuum ranging from extremely traditional, adult-centered beliefs to the opposite extreme, more progressive or child-centered. Teachers holding more traditional or adult-centered beliefs would agree with items such as "The most important thing to teach children is absolute obedience to whoever is in authority." In contrast, teachers with more progressive or child-centered beliefs would show more agreement with statements such as "Children learn best by doing things themselves rather than listening to others." The scale is composed of 16 items ranging from 1 (do not agree) to 5 (strongly agree). Thus, the scores range from the minimum score of 16 (which would reflect the most progressive or child-directed beliefs) to the maximum score of 90 (which would reflect the most traditional or adult-directed beliefs). Scores were derived by taking the mean of all items, 
with child-centered learning beliefs reversed-scored. Cronbach's alpha for this scale was reported as .84 by the scale's authors, and was .79 in our sample.

\section{Data analysis}

To address RQ 1 and RQ2, we conducted non-parametric tests for related samples on teachers' priority rankings and PD needs ratings regarding the seven learning areas. This statistical test allowed us to explore differences in teachers' priorities and PD needs across learning areas. To answer RQ3, we ran non-parametric correlations to explore associations between scores drawn from the 'Modernity Scale' and teachers' rankings of learning areas, on the one hand, and teachers' self-reported PD needs, on the other hand. Additionally, non-parametric correlation analyses were conducted to explore whether the demographic variables of teachers' age, years of teaching experience, and level of education were associated with different prioritizations of the learning areas, with different PD needs, or with different beliefs on education and how children learn.

\section{Results}

Findings are presented in three sub-sections, which correspond to the three RQs of the study. Note that the non-parametric correlation analyses conducted to explore the associations between the demographic variables (i.e., teachers' age, years of teaching experience, and level of education) and the three constructs under examination (i.e., prioritizations of the learning areas, PD needs, beliefs on education and how children learn) did not reveal any statistically significant relationships ( $p$ s > .05).

\section{RQ1: How do Singapore kindergarten teachers prioritize the importance of the learning areas?}

Figure 1 shows the ranking of the seven learning areas according to importance expressed by teachers in their responses. For easier interpretation, the figure was produced by converting the scores gathered in our questionnaire, in such a way that the longer the bar is, the higher the importance given by teachers to the learning area at hand.

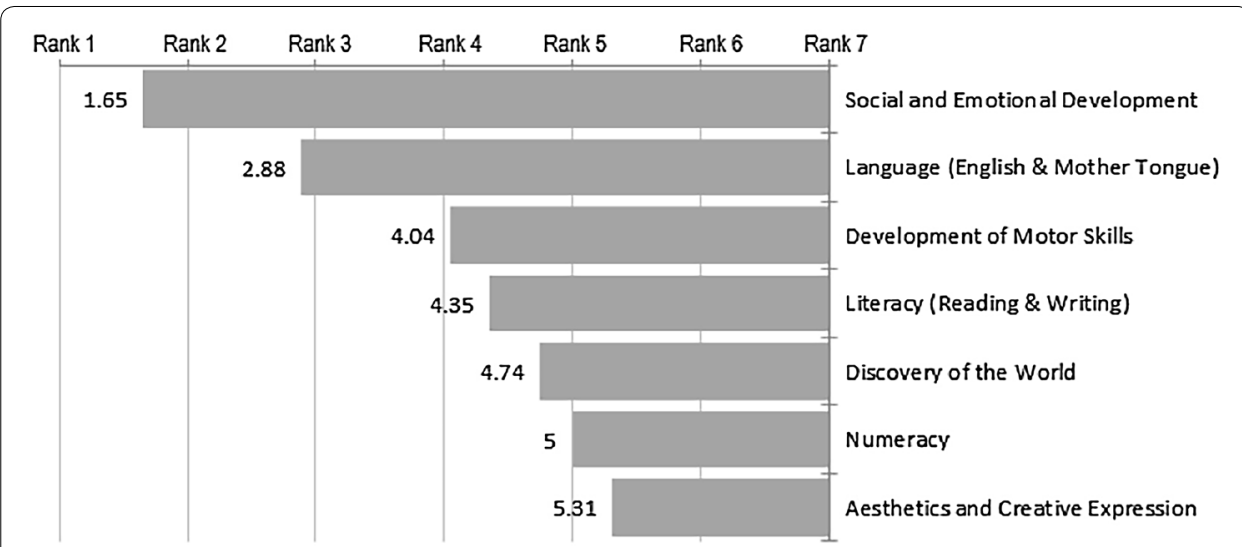

Fig. 1 Mean priority ranks for the seven learning areas (Rank 1 most important; Rank 7 least important) 
A Friedman test was conducted to evaluate differences among teachers' reported rankings. The test was significant, $\chi^{2}(6, N=123)=268.72, p<.0001$, and the corresponding Kendall's $W$ of .36 indicated strong differences among the ratings of the different learning areas. As displayed in Fig. 1, Singapore kindergarten teachers regarded Social and Emotional Development and Language (English and Mother Tongue) as the most important learning areas in early childhood education. Pairwise comparisons were conducted to explore any significant difference between the top-ranked areas. A Wilcoxon Signed-ranks test confirmed that Social and Emotional Development was ranked as the most important learning area $(\mathrm{Mdn}=1, p s<.0001]$. Figure 1 also shows that Numeracy and Aesthetics and Creative Expression were regarded as the least important areas. Pairwise comparisons (Wilcoxon Signed-ranks test) did not reveal any difference for teachers' rankings between Numeracy $(\mathrm{Mdn}=5)$ and Aesthetics and Creative Expression (Mdn =6), $[Z=1.21, p>.05]$, and between Numeracy $(\mathrm{Mdn}=5)$ and Discovery of the World $(\mathrm{Mdn}=5),[Z=1.17, p>.05]$. This result indicates that kindergarten teachers in Singapore consider these two areas equally important, within the low range of importance.

A closer look at the frequencies (see Table 1) provides us with further details. Whereas a large portion of the sample ranked Social and Emotional Development as the most important learning area, the frequencies related to the least important learning areas were rather diverse. It is interesting to note that none of the participants ranked Social and Emotional Development at the sixth or seventh placement. Similarly, notice that none of the participants ranked Numeracy and Aesthetics and Creative Expression as the most important learning areas. In contrast, Aesthetics and Creative Expression was ranked as the least important area by the largest percentage of teachers (30.9\%).

RQ2: What are Singapore kindergarten teachers' PD needs regarding the learning areas?

Figure 2 shows the results (means) obtained for each of the seven learning areas with regards to kindergarten teachers' PD needs, from 1 (no need for further training at all) to 4 (high level of need). Note that means ranged from 2.90 to $3.26(M=3.09, \mathrm{SD}=0.12)$. Variability was therefore small, which suggests that Singapore kindergarten teachers have moderate to high levels of need for further training in all learning areas of the NEL curriculum.

Singapore kindergarten teachers expressed the highest level of need for further training in Discovery of the World, followed by Aesthetics and Creative Expression, Literacy

Table 1 Percentage of teachers per learning area and rank

\begin{tabular}{|c|c|c|c|c|c|c|c|}
\hline & $1(\%)$ & $2(\%)$ & $3(\%)$ & $4(\%)$ & $5(\%)$ & $6(\%)$ & $7(\%)$ \\
\hline Social and emotional development & 67.5 & 15.4 & 4.9 & 8.9 & 3.3 & - & - \\
\hline Language (English and mother tongue) & 22.0 & 30.1 & 19.5 & 6.5 & 12.2 & 7.3 & 2.4 \\
\hline Development of motor skills & 2.4 & 25.2 & 14.6 & 17.1 & 16.3 & 13.0 & 11.4 \\
\hline Literacy (reading and writing) & 5.7 & 11.4 & 18.7 & 15.4 & 22.0 & 8.9 & 17.9 \\
\hline Discovery of the world & 2.4 & 8.9 & 17.1 & 21.1 & 7.3 & 19.5 & 23.6 \\
\hline Numeracy & - & 2.4 & 14.6 & 15.4 & 28.5 & 25.2 & 13.8 \\
\hline Aesthetics and creative expression & - & 6.5 & 10.6 & 15.4 & 10.6 & 26.0 & 30.9 \\
\hline
\end{tabular}




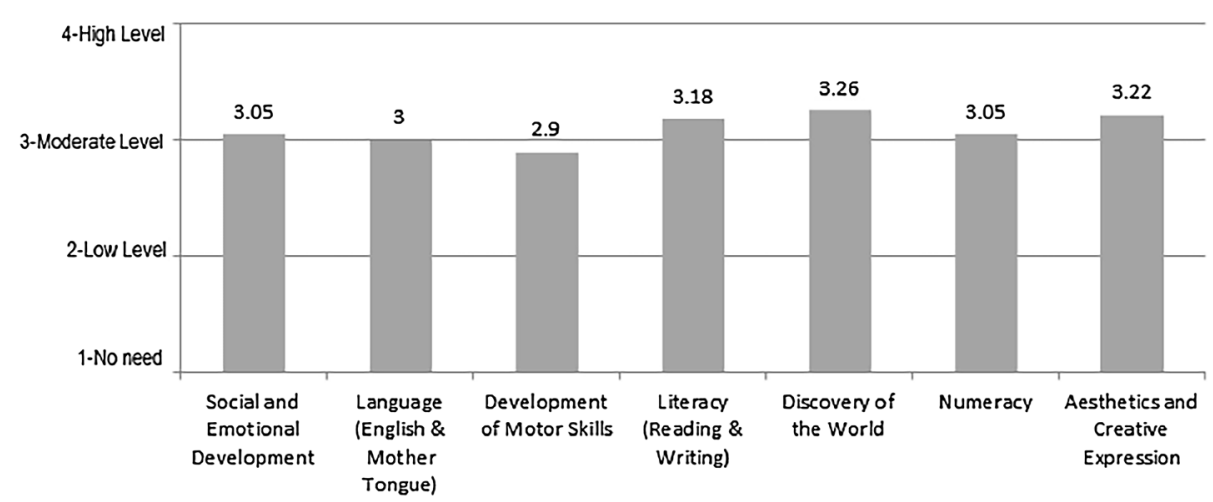

Fig. 2 Mean levels of teachers' PD needs in the seven learning areas (1 - no need at all, 2-low level of need, 3-moderate level of need and 4-high level of need)

(Reading and Writing), Numeracy, Social and Emotional Development as well as Language (English and Mother Tongue). The lowest level of need related to Development of Motor Skills. A significant Friedman test, $\chi^{2}(6, N=123)=48.57, p<.0001$, indicated that there were some differences among the reported levels of need. However, the corresponding Kendall's $W$ of .06 suggested the differences were weak. Indeed, pairwise comparisons using the Wilcoxon Signed-ranks test did not reveal significant differences between learning areas for which teachers expressed the highest and the lowest levels of need $(p>.05)$. This finding suggests that teachers have relatively similar levels of need for further training in the various learning areas. Interestingly, teachers reported the highest levels of need for further training in Discovery of the World and Aesthetics and Creative Expression despite the fact that these learning areas were ranked among the least important ones in RQ1. Table 2 shows that Discovery of the World and Aesthetics and Creative Expression were the two areas for which the highest percentages of teachers expressed moderate or high levels of need (totaling $87.8 \%$ and $87 \%$, respectively).

RQ3: Do teachers with different beliefs about children and how they learn differ in their priorities and PD needs?

First, we explored the association between teachers' beliefs about children's learning and how they learn and teachers' priorities in learning areas, on the one hand, and their selfreported PD needs, on the other hand. A Spearman correlation was conducted between scores drawn from the 'Modernity Scale', priority rankings with regard to the seven

Table 2 Percentage of teachers per learning area and level of PD needs

\begin{tabular}{lllll}
\hline & $\begin{array}{l}\text { No need } \\
\text { at all (\%) }\end{array}$ & $\begin{array}{l}\text { Low level } \\
\text { of need (\%) }\end{array}$ & $\begin{array}{l}\text { Moderate level } \\
\text { of need (\%) }\end{array}$ & $\begin{array}{l}\text { High level } \\
\text { of need (\%) }\end{array}$ \\
\hline Social and emotional development & 5.7 & 15.4 & 46.3 & 32.5 \\
Language (English and mother tongue) & 4.1 & 21.1 & 45.5 & 29.3 \\
Development of motor skills & 6.5 & 22.0 & 46.3 & 25.2 \\
Literacy (reading and writing) & 2.4 & 14.6 & 44.7 & 38.2 \\
Discovery of the world & 2.4 & 9.8 & 46.3 & 41.5 \\
Numeracy & 3.3 & 22.0 & 40.7 & 34.1 \\
Aesthetics and creative expression & 2.4 & 10.6 & 48.8 & 38.2 \\
\hline
\end{tabular}


Table 3 Spearman's rho correlations between 'Modernity Scale' scores and priority rankings (left column) and PD needs (right column)

\begin{tabular}{lcc}
\hline & Correlation priority rankings & Correlation PD needs \\
\hline Social and emotional development & $.253^{\mathrm{a}}$ & .048 \\
Language (English and mother tongue) & -.187 & .100 \\
Development of motor skills & .156 & .157 \\
Literacy (reading and writing) & $-.311^{\mathrm{a}}$ & .115 \\
Discovery of the world & $.235^{\mathrm{a}}$ & .159 \\
Numeracy & $-.196^{\mathrm{b}}$ & .094 \\
Aesthetics and creative expression & .160 & .065 \\
\hline
\end{tabular}

a Correlation is significant at the 0.01 level (2-tailed)

b Correlation is significant at the 0.05 level (2-tailed)

learning areas, and ratings on PD needs (see Table 3). Regarding priority rankings, there were significant correlations for the learning areas Social and Emotional Development, Discovery of the World, Numeracy, and Literacy (Reading and Writing). Teachers who indicated top priority for Social and Emotional Development and Discovery of the World showed more progressive or child-centered beliefs about children and how they learn. In contrast, teachers who ranked Numeracy and Literacy (Reading and Writing) as the top learning areas were more inclined towards traditional or adult-directed beliefs. No significant correlations were found between level of PD needs and teachers' approach to children's education.

\section{Discussion}

The first goal of the study was to investigate how Singapore kindergarten teachers ranked the importance of the learning areas outlined in the NEL curriculum framework (MOE 2013), thereby comparing the importance given to academic and non-academic areas. Based on prior research conducted in Asian countries (Berthelsen et al. 2011; Li and Rao 2005; Lim-Ratnam 2013), we expected that teachers would prioritize academic areas over non-academic areas due to societal expectations and family demands to prepare children for primary school. However, our data contradicted this anticipated result. In fact, the non-academic area Social and Emotional Development was found to be the top learning priority for teachers, followed by Language (English and Mother Tongue) (academic) and Development of Motor Skills (non-academic). These were followed by three academic areas, Literacy (Reading and Writing), Discovery of the World, and Numeracy. Finally, the non-academic area Aesthetics and Creative Expression was ranked least important.

The fact that academic and non-academic areas were intertwined in priority rankings suggests that teachers have internalized the importance of promoting children's holistic development (Bertram et al. 2016). Consistent with the principles described in the NEL framework, they seem to understand that their role as educators is not simply to deliver academic knowledge but rather to develop children holistically, by providing them with opportunities to foster their socio-emotional, linguistic, and motor development (Khoo 2010; Tan 2007). Having good socio-emotional skills, being emotionally mature, confident, and motivated, having a good linguistic command of English and the mother tongue (e.g., Mandarin, Malay, Tamil), and being physically healthy and with 
good motor skills seem to be much more important for teachers at this stage than the other learning areas. The fact that Numeracy was ranked at the 6th place was surprising, given the importance given to mathematics in Singapore from primary school onwards (Berthelsen et al. 2011). As discussed in the Introduction, we speculate that this result might be due to the increasing number of studies that stress the importance and benefits of 'learning through play' (e.g., Eggum-Wilkens et al. 2014; Gmitrová and Gmitrov 2003), as well as the numerous studies that relate early academic training to detrimental effects on individuals in the long term (e.g., Katz 2015). These findings are aligned with the studies conducted by Abry et al. (2015) and Piotrkowski et al. (2000) in the United States, who found that preschool and kindergarten teachers tend to prioritize the development of interpersonal competencies over academic skills. Moreover, teachers' emphasis on socio-emotional development is also aligned with a solid body of research that has demonstrated the strong link between young children's social-emotional skills and their cognitive development, language skills, mental health and later school success (for a literature review, see Juffer et al. 2008).

The second goal was to investigate Singapore kindergarten teachers' PD needs in terms of the learning areas of the NEL framework (MOE 2013). Our results showed that our participants had moderate to high levels of need for further training in all seven learning areas. Despite small variability, teachers expressed the highest demands for further training in contents related to Discovery of the World and Aesthetics and Creative Expression. This result is interesting because, as mentioned above, these two learning were lowest in teachers' priority rankings. The number of courses focused on science and arts/music offered by the post-secondary educational institutions in Singapore is typically lower than the number of courses on areas such as literacy, language, or numeracy. We speculate that this might be one of the factors contributing to teachers' higher training demands in these areas. Teachers interest in enhancing their preparation level shows that they acknowledge the relevance of science and arts/music in children's holistic development (Parsons 2004). In contrast, the lowest PD demands were identified for Development of Motor Skills, which suggests that teachers might not perceive the need to acquire specialized content knowledge on this matter.

Interestingly, the PD content solicited by kindergarten educators in Singapore does not match the international trends described in Schachter's (2015) literature review. Indeed, these international PD initiatives primarily focused on language and literacy instruction, followed by socio-emotional development. Perhaps because preservice teacher education programs already provide solid training in these content areas, Singapore kindergarten teachers prefer to further their learning in other domains such as the arts (Aesthetics and Creative Expression) and science (Discovery of the World).

Finally, our third goal was to examine whether teachers with different beliefs about children and how they learn differed in their priorities and PD needs regarding the seven learning areas. While we did not find any significant correlation between teachers' beliefs and their PD needs, we found interesting correlations with their prioritizations. In particular, we found that teachers with traditional or adult-centered beliefs tended to prioritize academically driven areas, in particular Numeracy and Literacy (Reading and Writing). In contrast, teachers with progressive or child-centered beliefs prioritized nonacademic areas such as Social and Emotional Development as well as Discovery of the 
World. Following Lim-Ratnam (2013), these findings suggest that traditionally oriented teachers might find it easier to satisfy societal expectations and family demands by 'drilling' children with worksheets, homework, and formal academic activities (Berthelsen et al. 2011). The concern of these teachers for academic skills would be well aligned with the mentality of many parents, not only in Asia (Ellis 2014; Li and Rao 2005) but also in Western countries such as the United States (Piotrkowski et al. 2000), who tend to favor the acquisition of disciplinary knowledge to expense of fostering children's holistic development.

It is surprising that none of the demographic variables correlated with different prioritizations of the learning areas, with different PD needs, or with different beliefs of children and how they learn. For example, based on the study conducted by Lara-Cinisomo et al. (2011), we expected that teachers with lower ECE academic qualifications would rank non-academically oriented learning areas higher, while teachers with higher academic qualifications might prioritize academically oriented areas. We also expected that the teacher age and years of teaching experience would allow us to identify differences in teachers' beliefs on education (e.g., the younger a teacher, the more progressive her beliefs) (Pajares 1992). However, our analysis did not reveal any significant correlations. Furthermore, in contrast with Fuligni et al. (2009), our analysis did not reveal any significant correlations between the demographic variables and teachers' PD needs in the different learning areas.

\section{Implications}

This study provides insights that may inform policy and practice concerning the design of PD initiatives that better meet the needs and interests of kindergarten teachers, not only in Singapore but also in countries with similar curricular and socio-cultural characteristics. For example, the low importance consistently given by Singapore teachers to Aesthetics and Creative Expression is somewhat concerning, as there is compelling evidence of the central role that the arts play in children's holistic development (Appel 2006). We speculate that this tendency might be due not only to teachers' perceived lack of preparation in this matter, as discussed above, but also to societal values and expectations, as parents in Singapore typically do not see the relevance of the arts in children's professional future (Bautista et al. 2016). In response to this, it is worth mentioning that the Singapore Government is currently implementing measures to enhance the role of the arts in children's life. For example, it has recently been announced that the National Arts Council will collaborate with an anchor operator to pilot the preschool 'Art Education Programme' in mid-2016 (Channel News Asia 2016). Time and resources should be offered to preschool principals, teachers, and staff in order to reach a unified vision of what children should learn and be able to do during preschool years and at school entry, always in constant dialogue with parents (Piotrkowski et al. 2000).

Singapore kindergarten teachers seem eager to further enhance their knowledge, skills, and dispositions across the various curriculum areas, which evidences the central role played by local PD providers (Bautista et al. 2015). Interestingly, the proportion of PD courses and workshops offered in Singapore seems consistent with teachers' own demands (ECDA 2016). Recall that our analysis of the most recent 'Prospectus' indicated that most PD initiatives focused on Aesthetics and Creative Expression followed 
by Discovery of the World, whereas the least number of courses were offered for Motor Skills Development and Social and Emotional Development. Content wise, therefore, it seems that PD is well aligned with teachers' own learning demands. This high degree of responsiveness-or coherence with teachers' needs-is one of the essential features for effective PD (Bautista and Ortega-Ruíz 2015).

Singapore has made tremendous efforts in the past years to enhance the quality of ECE. Because preschool education matters, preschool teachers are adequately provided with a wide range of initiatives to foster their continuous learning. This kind of support, unfortunately, is rather rare in other nations, where preschool teachers commonly get "the short end of the stick" when it comes to PD, as compared to primary or secondary teachers (Coxa et al. 2015). Thus, policymakers and administrators in other nations should also provide sufficient funds for joint curriculum planning and teacher training, which will allow countries to better develop their ECE infrastructures (Kagan et al. 2013).

\section{Limitations and future work}

This study is not exempt of limitations. First, the results come from a single source of data (i.e., online questionnaire). It would be desirable to conduct studies based on other data sources (e.g., interviews, focus group discussions, classroom observations) to continue to investigate our research questions more deeply. Second, given the exploratory nature of this specific study, teachers' prioritization of the learning areas and PD needs were studied through single item measures. Thus, the psychometric properties of our measurement instrument should be improved in the future. Finally, it would be relevant to conduct studies with larger sample sizes in order to establish more fine-grained comparisons among teachers with different socio-demographic profiles (e.g., age, years of teaching experience, educational background).

\section{Authors' contributions}

$A B$ is one of the Co-Principal Investigators of the 'Singapore Kindergarten Impact Project' (SKIP). He conceptualized this particular study, designed the data collection instrument, and lead the writing of the paper. SCN and DM are Research Assistant and Research Fellow on SKIP, respectively. They were responsible for the literature review, data collection, statistical analyses, and reporting of findings. RB is the Principal Investigator of SKIP. She conceptualized the research project, assisted in the design of the data collection instrument, and contributed to the writing and proofreading of the paper.

All authors read and approved the final manuscript.

\section{Acknowledgements}

This study was funded by the Education Research Funding Programme, National Institute of Education (NIE), Nanyang Technological University, Singapore, project no. OER 09/14RB. Singapore Kindergarten Impact Project (SKIP). The views expressed in this paper are those of the authors and do not necessarily represent the views of NIE. The authors would like to offer a sincere thanks to the three Reviewers and Editors who offered thoughtful comments, specific critiques, and questions to guide revisions that strengthened this manuscript significantly. Many thanks also to all our colleagues from the SKIP research team.

\section{Competing interests}

The authors declare that they have no competing interests.

Received: 3 July 2016 Accepted: 16 November 2016

Published online: 25 November 2016

\section{References}

Abry, T., Latham, S., Bassok, D., \& LoCasale-Crouch, J. (2015). Preschool and kindergarten teachers' beliefs about early school competencies: Misalignment matters for kindergarten adjustment. Early Childhood Research Quarterly, 31 , 78-88. 
Anders, Y. (2015). Literature review on pedagogy. Paris: OECD.

Appel, M. P. (2006). Arts integration across the curriculum. Leadership, 36(2), 14-17.

Bassok, D., Latham, S., \& Rorem, A. (2015). Is kindergarten the new first grade? EdPolicyWorks Working Paper Series, No. 20.

Bautista, A., \& Ortega-Ruíz, R. (2015). Teacher professional development: International perspectives and approaches. Psychology, Society and Education, 7(3), 240-251.

Bautista, A., Pérez Echeverría, M. P., \& Pozo, J. I. (2010). Music performance teachers' conceptions about learning and instruction: A descriptive study of Spanish piano teachers. Psychology of Music, 38(1), 85-106.

Bautista, A., Tan, L. S., Ponnusamy, L. D., \& Yau, X. (2016). Curriculum integration in arts education: Connecting multiple art forms through the idea of 'space'. Journal of Curriculum Studies, 48(5), 610-629. doi:10.1080/00220272.2015.1089940.

Bautista, A., Wong, J., \& Gopinathan, S. (2015). Teacher professional development in Singapore: Depicting the landscape. Psychology, Society and Education, 7(3), 311-326.

Bennett, J., \& Kaga, Y. (2010). The integration of early childhood systems within education. International Journal of Child Care and Education Policy, 4(1), 35-43.

Berthelsen, D., Brownlee, J., \& Karuppiah, N. (2011). Teaching beliefs and practices in early childhood education in Singapore. Singapore: Pearson Education.

Bertram, T., Pascal, C., Cummings, A., Delaney, S., Ludlow, C., Lyndon, H., \& Stancel-Piatak, A. (2016). Early childhood policies and systems in eight countries: Findings from IEA's early childhood education study. International Association for the Evaluation of Educational Achievement.

Chan, B., Lee, M., \& Choy, G. (2009). Competing forces: Government policy, teacher education, and school administration in Hong Kong early childhood education. International Journal of Child Care and Education Policy, 3(1), 75-86.

Channel News Asia. (2016). Arts-based approach in pre-school setting to be piloted this year. http://www.channelnewsasia. $\mathrm{com} /$ news/singapore/arts-based-approach-in/2695030.html.

Coxa, M. E., Hollingsworthb, H., \& Buysse, V. (2015). Exploring the professional development landscape: Summary from four states. Early Childhood Research Quarterly, 32, 116-126.

Darling-Hammond, L., Chung Wei, R., \& Andree, A. (2010). How high-achieving countries develop great teachers. Stanford Center for Opportunity Policy in Education Research Brief, pp. 1-8.

Driscoll, K. C., \& Pianta, R. C. (2010). Banking time in head start: Early efficacy of an intervention designed to promote supportive teacher-child relationships. Early Education and Development, 21(1), 38-64. doi:10.1080/10409280802657449.

Early Childhood Development Agency (ECDA). (2013). Enhancing child care quality through continuing professional development. https://www.ecda.gov.sg/PressReleases/Pages/Enhancing-child-care-quality-through-continuingprofessional-development.aspx.

Early Childhood Development Agency (ECDA). (2016). Prospectus 2016. https://www.ecda.gov.sg/Pages/ContinuingProfessional-Development.aspx.

Eggum-Wilkens, N. D., Fabes, R. A., Castle, S., Zhang, L., Hanish, L. D., \& Martin, C. L. (2014). Playing with others: Head start children's peer play and relations with kindergarten school competence. Early Childhood Research Quarterly, 29(3), 345-356. doi:10.1016/j.ecresq.2014.04.008.

Ellis, N. J. (2014). Afraid to lose out: the impact of kiasuism on practitioner research in Singapore schools. Educational Action Research, 22(2), 235-250. doi:10.1080/09650792.2013.859088.

Fuligni, A. S., Howes, C., Lara-Cinisomo, S., \& Karoly, L. (2009). Diverse pathways in early childhood professional development: An exploration of early educators in public preschools, private preschools, and family child care homes. Early Education Development, 20(3), 507-526.

Gananathan, R. (2011). Implications of full day kindergarten program policy on early childhood pedagogy and practice. International Journal of Child Care and Education Policy, 5(2), 33-45.

Gmitrová, V., \& Gmitrov, J. (2003). The impact of teacher-directed and child-directed pretend play on cognitive competence in kindergarten children. Early Childhood Education Journal, 30(4), 241-246.

Hur, E., Jeon, L., \& Buettner, C. K. (2015). Preschool teacher's child-centered beliefs: Direct and indirect associations with work climate and job-related wellbeing. New York: Springer Science.

Ishimine, K., Tayler, C., \& Bennett, J. (2010). Quality and early childhood education and care: A policy initiative for the 21st century. International Journal of Child Care and Education Policy, 4(2), 67-80.

Juffer, F., Bakermans-Kranenburg, M. J., \& van ljzendoorn, M. H. (2008). Enhancing children's socioemotional development: A review of intervention studies. In: Handbook of research methods in developmental Science (pp. 213-232). New York: Blackwell Publishing Ltd.

Kagan, S. L., Castillo, E., Gomez, R. E., \& Gowani, S. (2013). Understanding and using early learning standards for young children globally. International Journal of Child Care and Education Policy, 7(2), 53-66.

Katz, L. G. (2015). Lively minds: Distinctions between academic versus intellectual goals for young children. Boston: Defending the early years. https://deyproject.files.wordpress.com/2015/04/dey-lively-minds-4-8-15.pdf.

Khoo, K. C. (2010). The shaping of childcare and preschool education in Singapore: From separatism to collaboration. International Journal of Child Care and Education Policy, 4(1), 23-34.

Lara-Cinisomo, S., Fuligni, A. S., \& Karoly, L. A. (2011). Preparing preschoolers for kindergarten: A look at teacher beliefs. In D. M. Laverick \& M. R. Jalongo (Eds.), Transitions to early care and education: International perspectives on making schools ready for young children (pp. 93-106). New York: Springer.

Li, H., \& Rao, N. (2005). Curricular and instructional influences on early literacy attainment: Evidence from Beijing, Hong Kong and Singapore. International Journal of Early Years Education, 13(3), 235-253. doi:10.1080/09669760500295870.

Lim-Ratnam, C. (2013). Tensions in defining quality pre-school education: The Singapore context. Educational REview, 65(4), 416-431. doi:10.1080/00131911.2012.707641

Ministry of Education (MOE). (2003). Launch of pre-school curriculum framework. http://www.moe.gov.sg/media/ press/2003/pr20030120_print.htm.

Ministry of Education (MOE). (2013). Nurturing early learners: A curriculum for kindergartens in Singapore. Educators' guide: overview. https://www.moe.gov.sg/docs/default-source/document/education/preschool/files/nel-edu-guideoverview.pdf. 
NICHD Early Child Care Research Network (Ed.). (2006). Child care and child development: Results from the NICHD study of early child care and youth development. London: Guilford Press.

Organisation for Economic Co-operation and Development (OECD). (2015). Starting strong IV: Monitoring quality in early childhood education and care doi: 10.1787/9789264233515-en.

Pajares, M. F. (1992). Teachers' beliefs and educational research: Cleaning up a messy construct. Review of Research in Education, 62, 307-332.

Parsons, M. (2004). Art and integrated curriculum. In E. W. Eisner \& M. D. Day (Eds.), Handbook of research and policy in art education (pp. 775-794). Mahwah, NJ: Lawrence Earlbaum Publishers.

Pence, A., \& Pacini-Ketchabaw, V. (2010). Both/and: Reflections on recent anglo/western early childhood curriculum statements. International Journal of Child Care and Education Policy, 4(2), 15-24.

Pianta, R. C. (2016). Teacher-student interactions: Measurement, impacts, improvement, and policy. Policy Insights from the Behavioral and Brain Sciences, 3(1), 98-105.

Piotrkowski, C. S., Botsko, M., \& Matthews, E. (2000). Parents' and teachers' beliefs about children's school readiness in a high-need community. Early Childhood Research Quarterly, 15(4), 537-558.

Schachter, R. E. (2015). An analytic study of the professional development research in early childhood education. Early Education and Development, 26, 1057-1085.

Schaefer, E. S., \& Edgerton, M. (1985). Parent and child correlates of parental modernity. In I. E. Sigel (Ed.), Parental belief systems: The psychological consequences for children (pp. 287-318). New York: Psychology Press.

Shanmugaratnam, T. (2003). Speech by Mr. Tharman Shanmugaratnam Senior Minister of State for Trade and Industry and Education Official Launch cum Seminar of MOE'S Pre-school Curriculum Framework at Nanyang Polytechnic Auditorium. http://www.moe.gov.sg/media/speeches/2003/sp20030120.htm.

Stipek, D., \& Byler, P. (1997). Early childhood education teachers: Do they practice what they preach? Early Childhood Research Quarterly, 12, 305-325.

Tan, C. T. (2007). Policy developments in preschool education in Singapore: A focus on the key reforms of kindergarten education. International Journal of Child Care and Education Policy, 1(1), 35-43.

Todd, R. J. (2010). Curriculum integration. Learning in a changing world. Victoria, AU: McPerson's Printing Group.

Wall, S., Litjens, I., \& Taguma, M. (2015). Early childhood education and care pedagogy review: England. Paris: OECD.

\section{Submit your manuscript to a SpringerOpen ${ }^{\circ}$ journal and benefit from:}

- Convenient online submission

$\checkmark$ Rigorous peer review

- Immediate publication on acceptance

Open access: articles freely available online

- High visibility within the field

- Retaining the copyright to your article

Submit your next manuscript at $>$ springeropen.com 